\title{
DE REPENTE TUDO MUDOU: LIDERANDO EM TEMPOS DE CRISE
}

\section{SUDDENLY EVERYTHING HAS CHANGED: LEADING IN TIMES OF CRISIS}

\author{
RENATA FREIRE DE ALMEIDA \\ Mestranda PPG em Administração - Universidade do Vale do Itajaí (UNIVALI) \\ Orcid: https://orcid.org/0000-0002-7851-8593 / E-mail: renatafalmeida@gmail.com \\ Endereço: Rua João Coan, n. 400, Centro - Biguaçu, SC, CEP: 88161-064 \\ LUIZ HENRIQUE DA SILVA \\ Mestre em Administração - Universidade do Vale do Itajaí (UNIVALI) \\ Orcid: http://orcid.org/0000-0002-7076-831X / E-mail: luizhenrique301@hotmail.com
}

\begin{abstract}
TATIANA GHEDINE
Professora do PPG em Administração e Programa de Mestrado Profissional em Gestão Empresarial, Internacionalização e Logística - Universidade do Vale do Itajaí (UNIVALI)

Doutora em Administração - Universidade Federal do Rio Grande do Sul (UFRGS)

Orcid: https://orcid.org/0000-0002-4006-3917 / E-mail: tghedine@univali.br
\end{abstract}

\begin{abstract}
ANETE ALBERTON
Professora do PPG em Administração e Programa de Mestrado Profissional em Gestão Empresarial, Internacionalização e Logística - Universidade do Vale do Itajaí (UNIVALI)

Doutora em Engenharia de Produção pela Universidade Federal de Santa Catarina (UFSC) Orcid: https://orcid.org/0000-0002-6477-0122 / E-mail: anete@univali.br
\end{abstract}

Submissão: 15/08/2020. Revisão: 20/11/2020. Aceite: 19/12/2020. Publicação: 29/12/2020. DOI: http://dx.doi.org/10.22277/rgo.v14i1.5748

\section{RESUMO}

O caso retrata a história de Caterine, líder de Gestão de Pessoas da startup XPTO, que enfrenta um cenário de crise da pandemia da COVID-19, precisando propor soluções para gerenciar o principal ativo da XPTO, as pessoas. Para isso, Caterine necessita definir como coletar, compreender e projetar informações em um cenário de crise e incertezas, além de decidir como elaborar um plano de ações para área de Gestão de Pessoas de forma que proteja as pessoas e mantenha o negócio sustentável. O presente caso tem como objetivo permitir aos alunos vivenciar o desafio de compreender e projetar informações em tempos de crise e incertezas, apresentando um cenário dinâmico de constantes mudanças no contexto de uma empresa startup. O caso foi desenvolvido para abordar a Teoria Contingencial propondo a utilização do "POP-DOC Loop", uma ferramenta para avaliar situações em momentos de crise e auxiliar no processo de tomada de decisão. Este caso é baseado em fatos reais, para sua construção foram utilizados dados coletados por meio de duas entrevistas online, semiestruturadas, com o Head of People de uma startup, e pode ser utilizado para ensino no curso de Graduação em Administração, nas disciplinas de Teoria Geral da Administração, Gestão de Pessoas, Liderança e Estratégia Empresarial.

Palavras-chave: Liderança em crise. POP-DOC Loop. Teoria Contingencial. 


\begin{abstract}
This case portrays the story of Caterine, the People Management leader of the startup XPTO, which faces the COVID-19's pandemic in a crisis scenario, needing to propose solutions to manage XPTO's main asset, people. To achieve it, Caterine needs to decide how to collect, understand and project information in a scenario of crisis and uncertainty, and in addition she needs to decide how to develop an action plan for People Management in a way that protect people and assure the business's sustainability. The present case aims to promote students the experience of facing a challenge, understanding, and projecting information in times of crisis and uncertainty, presenting a dynamic scenario of constant changes in the context of a startup company. The case was developed to address the Contingency Theory proposing the use of the "POP-DOC Loop", a tool to assess situations in times of fast changes and assist the leadership at the decision-making process. This case is based on real facts which were collected through two online interviews, semi-structured, with the Head of People of a startup, and it can be used for teaching in the Undergraduate course in Business, at the General Administration Theory, People Management, Leadership and Business Strategy.
\end{abstract}

Keywords: Crisis leadership. POP-DOC Loop. Contingency Theory.

\title{
1 INTRODUÇÃO
}

O dia 12 de março de 2020 prometia ser como todos os outros dias de Caterine na empresa XPTO. Contratada desde outubro do ano anterior, contava com 5 meses na empresa e, em velocidade acelerada, havia completado seu ciclo de integração e proposto diversos projetos de Gestão de Pessoas (GP), aprovados e implantados. Na XPTO pela primeira vez em sua carreira ouviu o mote: "Queimar o caixa rápido para crescermos rápido". Por esta razão, os programas de GP precisavam ser assertivos, rápidos e contar com os melhores profissionais e consultores, sempre que possível. Sua contratação aconteceu em um momento de tração da empresa, em que executivos estavam sendo contratados diretamente do mercado com o objetivo de proporcionar maior robustez para o negócio e trazer conceitos de governança para que a XPTO crescesse de forma sustentada.

Naquele dia, 12 de março de 2020, notícias de uma pandemia que já circulavam nas mídias desde o final de 2019, se mostraram mais preocupantes para o cenário brasileiro, com a declaração da Organização Mundial de Saúde (OMS) de estado de emergência oficial para a pandemia. No Brasil havia 52 casos confirmados da doença e os primeiros de transmissão comunitária (quando não se sabe a origem da transmissão) tinham ocorrido naquela semana.

Ainda cedo, Sérgio, CEO da startup XPTO e chefe direto de Caterine, chamou-a à sua sala. Ao chegar lá, ela percebeu que ele já estava em reunião com os heads de outras áreas. Logo que ela se sentou Sérgio a questionou:

- Caterine, você viu as notícias sobre esse tipo de coronavírus que estão chamando aí de COVID-19? Parece que dessa vez está indo muito além da China.

- Vi sim, inclusive a OMS se pronunciou ontem. Na Itália a situação é preocupante, na segunda-feira, dia 9 de março de 2020, entraram em lockdown. Precisamos ficar atentos aos sinais aqui no Brasil agora - disse prontamente orgulhosa por se manter atualizada diariamente quanto às notícias globais.

Sérgio prossegue:

- Justamente por isso estou me reunindo com vocês hoje. Percebi acompanhando os movimentos em outros países que não devemos ser pegos de surpresa. Precisamos pensar o 
que faremos com nossos colaboradores se a situação se agravar. O fato de termos transmissão comunitária no Brasil só nos deixa ainda mais em alerta.

- Bom, fazemos assim, vou elaborar um plano de ação, possivelmente começando com um grupo piloto. Apresento uma proposta amanhã no primeiro horário para trabalharmos sobre esse plano, o que acham? - sugere Caterine.

- Ótima ideia! - disse Sérgio.

De volta a sua mesa, Caterine respirou fundo e se perguntou: "Por onde começar?"

\section{CATERINE E A EMPRESA XPTO}

Caterine possui 15 anos de experiência na área de GP, tendo atuado nos mais diversos subsistemas em diferentes organizações, desde setores de tecnologia até o varejo. Apesar de graduada em psicologia, pouco aplicou na prática sua formação, sempre recorrendo a ferramentas da administração, conforme identificava a necessidade de atingir algum resultado específico demandado pela empresa. Em sua trajetória profissional Caterine trabalhou nos processos de recrutamento, seleção e remuneração, tendo coordenado equipes de folha de pagamento e benefícios, além de ter atuado como business partner.

Decidiu-se mudar de São Paulo, onde viveu até então, para Florianópolis em 2018, quando retornou para o setor de tecnologia de informação. Em outubro de 2020 aceitou o desafio de liderar e estruturar os processos de GP na startup XPTO. Com uma cultura diferente de todas as outras empresas nas quais trabalhou, ela precisou se ajustar rapidamente para acompanhar o ritmo da XPTO, que requer adaptabilidade, entregas de alto nível e promoção da escalabilidade.

A empresa XPTO é uma startup presente no mercado brasileiro desde 2016, fundada por 2 sócios em Florianópolis/SC através de um reduzido recurso financeiro e uma pequena equipe de trabalho. Atualmente conta com 150 colaboradores no seu quadro de pessoal, em sua grande maioria, recém-formados ou com pouca experiência de mercado. Tem como proposta o SaaS (Sigla para Support as a Service, suporte como serviço), oferecendo uma plataforma para a gestão de atendimento a clientes, permitindo sua automação e gestão. Como característica de empresas startups, teve crescimento de dois dígitos por dois anos seguidos até receber o aporte financeiro de uma Venture Capital, em setembro de 2019. Até então sua gestão foi realizada diretamente pelos sócios, mas a partir do investimento de $\mathrm{R} \$ 8$ milhões de reais, a empresa deu uma guinada necessária e até normal no mercado de startups para poder gerar escalabilidade.

A contratação de heads das principais áreas e a instalação de uma nova sede na cidade de Florianópolis foram providências tomadas imediatamente após o aporte financeiro. "Queimar caixa" é um fator comum às empresas que recebem investimento. Como exemplo, a grande quantidade de celebrações realizadas pela XPTO. Happy hours e as festas de aniversários são corriqueiras. "Gastamos mais do que temos de receita - é a premissa de uma startup".

Os gestores da XPTO atuam em um ecossistema incerto, lidando sob diferentes perspectivas, sejam elas, mercado, produtos ou pessoas. Eles trabalham sob constante pressão e necessitam agir rapidamente, "errar rápido para poder acertar rápido" este é o mantra entre eles, caso contrário a existência da empresa pode ser comprometida, uma vez que o mercado de tecnologia da informação (TI) se concentra em um segmento de constante inovação.

Até setembro de 2019, na contratação de especialistas de mercado para liderarem suas áreas de conhecimento, a empresa não possuía processos estruturados e que 
permitissem a escalabilidade. Também não havia um olhar para os indicadores das áreas, evidenciando as dores do crescimento de uma empresa "acelerada" como a XPTO. Por esta razão a busca urgente de profissionais no mercado com "bagagem" e visão sobre indicadores para implementar isso "pra ontem" na startup.

O aporte financeiro recebido em setembro de 2019 viabilizou os negócios por 9 meses, com breakeven em junho de 2020. Em janeiro de 2020, os sócios iniciaram uma nova rodada de captação de investimento visando a internacionalização do negócio. Ao "embarcar" profissionais experientes do mercado para liderarem as áreas da empresa, foi necessário o cuidado sob dois aspectos: o primeiro, em não perder a essência da cultura organizacional instalada até então, evitando grandes rupturas no processo de profissionalização das áreas e, o segundo, estabelecer e descrever os processos sem que a organização perdesse velocidade e flexibilidade, e ainda assim direcionar para qual sentido se organizariam e priorizariam seus processos.

Foi nesse turbilhão de mudanças e reestruturações que Caterine entrou. Até o mês de março de 2020 ela havia proposto algumas ações para sua área visando, dentre elas o mapeamento de cultura organizacional, que não tinha uma base clara inicialmente na XPTO. Porém, a ação foi suspensa até que se desenhasse o futuro desejado no que diz respeito à cultura da empresa. No momento, o trabalho da área tem sido em fortalecer os valores existentes, além disso a formação de liderança é uma prioridade na agenda da Caterine desde a sua contratação. Em função disso, treinamentos como o de inteligência emocional foram implementados no início de 2020.

Apesar de ser uma empresa de tecnologia, a cultura de home office não estava consolidada, e a prática era utilizada apenas pontualmente para atender a demandas pessoais. A proposta de uma política de home office chegou a ser apresentada por Caterine em janeiro de 2020, porém, o tema não foi adiante em discussões uma vez que outros temas tinham prioridade. Caterine percebeu em processos seletivos, a dificuldade em captar talentos pelo interesse destes de residirem em cidades diferentes da cidade em que a empresa XPTO está localizada. Segundo os indicadores de Recrutamento e Seleção da empresa, dos 6\% dos candidatos aprovados, $38 \%$ não aceitam a proposta de trabalho por não terem a modalidade de home office como opção em suas rotinas. Em outros casos, profissionais solicitavam seu desligamento por decidirem acompanhar seus cônjuges em experiências internacionais ou em outras localidades no Brasil. No início de janeiro de 2020 foi aplicado um Net Promoter Score (NPS) para medir a satisfação de seus profissionais. Dentre os pontos abordados pelos colaboradores, destacaram-se o day off na data do aniversário e o home office, como benefícios solicitados por $40 \%$ deles.

\section{COVID-19, LOCKDOWN E HOME OFFICE}

Em sua mesa, após a reunião do dia 12 de março de 2020, Caterine estava apreensiva com a atual situação do cenário pandêmico causado pela COVID-19. Resolveu buscar mais detalhes para compreender os efeitos da pandemia no Brasil e preparar um plano de ação para apresentar na reunião do dia seguinte. Ela pensou "temos apenas 2 casos da doença confirmados em Santa Catarina, mas a OMS declarou pandemia de coronavírus... Acho que não será algo assim tão trivial esta doença". Diante disso, Caterine analisou que países como França, Itália e Espanha haviam declarado lockdown e concluiu que provavelmente no Brasil não seria diferente. Sendo assim, não restaria para a XPTO uma alternativa diferente do que o home office. Diante disso, Caterine decidiu propor um plano de contingência para que a 
empresa se preparasse caso a COVID-19 se propagasse na região de Florianópolis. Nesse plano, a empresa contaria com $20 \%$ de cada uma das equipes trabalhando em home office, a partir da próxima segunda-feira, 16 de março de 2020. Seria um bom teste para ver como isso afetaria a rotina de trabalho da XPTO.

Na reunião, como acordado, Caterine apresentou sua proposta ao CEO e os demais líderes da empresa, que decidiram pela aprovação do plano de ação. Porém, ela e os heads das áreas teriam apenas um dia para organizar processos e equipes para trabalhar de forma híbrida, com parte da equipe no escritório e parte em casa. Seguiriam as próximas semanas acompanhando os avanços da pandemia no estado de Santa Catarina, para verificar as mudanças no ambiente externo.

Sexta-feira, 13 de março de 2020, ficou marcado como um dia caótico para garantir a organização e alinhamento entre as equipes. Quem ficaria em casa? Quais processos poderiam ser executados remotamente? Como manter as pessoas alinhadas e engajadas mesmo sem ocuparem o mesmo espaço? Essas e outras preocupações perseguiram Caterine e sua equipe naquele dia. Nesse dia, para garantir o alinhamento de todos os colaboradores quanto às motivações da tomada de decisão da empresa e seu plano de ação, Caterine centralizou na área de GP a comunicação aos colaboradores. Após as conversas individuais dos heads de área com suas equipes e profissionais escolhidos para trabalhar em home office, Caterine emitiu um comunicado pelas ferramentas de e-mail e slack em nome da área de GP, abordando o atual cenário da COVID-19. Contudo, todo o processo para trabalhar com equipes híbridas foi concluído aparentemente com sucesso, mas a prova viria somente nas próximas semanas, através do acompanhamento das atividades.

\section{MUDANÇA DE PLANOS}

Apesar de tudo, Caterine estava se sentido desconfortável com as notícias relatadas nas mídias sobre a COVID-19 no Brasil, a situação se agravava, repleta de especulações e fatos inverídicos. Diante desse cenário, no sábado, dia 14 de março de 2020, Caterine entrou em contato com Sérgio, o CEO da empresa, e recomendou formarem um comitê de crise via WhatsApp, composto pelos heads de áreas, para compartilhar e orientar as ações a serem tomadas, a fim de proteger as pessoas e manter o negócio sustentável em um ambiente até então desconhecido. No mesmo dia, após a criação do comitê de crise, Caterine sugeriu que fizessem um benchmarking com empresas do segmento para acompanhar quais iniciativas estavam sendo tomadas quanto à gestão de pessoas. Com o resultado do benchmarking, o consenso foi que a situação poderia se agravar em poucos dias.

O comitê percebeu que com esses indicativos do mercado poderia ser mais prudente contar com toda a sua equipe segura em casa. Juntos, ainda no sábado, os líderes chegaram à conclusão que a incerteza das consequências ao manter as pessoas indo para o escritório trabalhar, trariam um maior risco do que as possíveis fragilidades trabalhistas do teletrabalho. Foi unânime a decisão de que a partir de segunda-feira, dia 16 de março de 2020, 100\% dos colaboradores trabalhariam em home office. $O$ comitê de crise também decidiu prontamente estabelecer uma única fonte de oficial de informações, com a curadoria das principais informações a respeito da COVID-19, consolidados nas visões do mundo, do Brasil, do estado de Santa Catarina, de Florianópolis e por fim da empresa. Esse material seria disponibilizado para toda a comunidade interna e externa, incluindo clientes, fornecedores e demais empresas do ecossistema à qual a XPTO pertence. Outra decisão tomada pelo comitê de crise, foi que todos os comunicados aos colaboradores fossem concentrados na figura do CEO, nas comunicações por whatsApp, slack e e-mail, com o intuito de passar uma sensação de maior 
segurança em um momento em que todos estavam se sentindo "perdidos" frente esta nova realidade.

No domingo, os esforços do comitê de crise seriam em operacionalizar o trabalho em home office. O líder de $\mathrm{TI}$, ficou com a responsabilidade de trabalhar com sua equipe para distribuir os equipamentos e preparar softwares de trabalho remoto para todo o contingente. O líder de infraestrutura, com a responsabilidade de organizar a distribuição de cadeiras e mobiliário, e o líder de marketing, ficou responsável por elaborar a base de informações que serviria como única fonte de informação. Caterine e sua equipe, ficaram com a responsabilidade de auxiliar os heads de área a entrarem em contato individual com cada um dos 140 colaboradores da empresa para comunicar a decisão. E posteriormente, ainda no domingo, o CEO emitiu um comunicado oficial da empresa por e-mail e slack sobre o trabalho em home office e compartilhou o link para a base de informações oficial da XPTO.

Como modelo de gestão, as reuniões de liderança que ocorriam semanalmente permaneceram na agenda, tendo a adição de reuniões diárias. Nessas reuniões, havia um breve relato do que foi feito no dia anterior e o que seria feito naquele dia, tendo em vista os indicadores de cada área. Nas reuniões semanais, que aconteciam presencialmente, tiveram como adaptação um foco ainda maior em indicadores, com um olhar ainda mais rigoroso. Foram identificados inclusive indicadores frágeis que não representavam eficácia para o negócio da empresa, como, por exemplo, indicadores de vendas de softwares, que não chegaram a ser implementados nos meses posteriores.

\section{UM TERMÔMETRO PARA A GESTÃO DE PESSOAS}

Duas semanas depois, ainda com todos os colaboradores trabalhando em home office, a preocupação com as pessoas era constante e os fatores externos que poderiam impactar em seu desempenho e performance eram inúmeros. Caterine decidiu por aplicar uma pesquisa NPS com seus colaboradores.

A pontuação da pesquisa foi 80 , próxima a um nível de excelência. Mesmo assim, a pesquisa contou com comentários da maioria dos colaboradores indicando parâmetros razoável ou ruim, com pontos de melhoria a serem ajustados pela GP. Caterine elaborou um relatório ressaltando os principais pontos identificados nos comentários realizados pelos colaboradores em cada pergunta realizada (Apêndice A).

\section{E AGORA?}

A empresa XPTO teve um crescimento vertiginoso até março de 2020 , o que justificava a expectativa de crescimento de três dígitos para 2020 e 2021. Diante destas perspectivas, com o aporte financeiro recebido em setembro de 2019, investiu em uma nova sede, como forma de se preparar para o crescimento em escala, inclusive da equipe. Agora, o cenário é outro. O resultado de vendas retraído em março de 2020 e a possibilidade de trabalho remoto por tempo indeterminado fizeram com que a gestão começasse a questionar seu modus operandi até aquele momento.

Caterine, head de GP, está na posição de propor soluções para gerir o principal ativo da XPTO, as pessoas. Ao final da segunda semana em home office, com os profissionais ainda se adequando ao novo formato de trabalho, Caterine se depara com o desafio de suprir as necessidades dos colaboradores indicadas pela pesquisa de NPS. Para isso Caterine precisa definir como coletar, compreender e projetar as informações em um cenário de crise e 
incertezas, além de decidir como elaborar um plano de ações para área de GP de forma que proteja as pessoas e mantenha o negócio sustentável.

\section{GLOSSÁRIO DE TERMOS}

Benchmarking: é um processo de pesquisa entre empresas para analisar como seus produtos, processos e serviços são realizados.

Breakeven: é o ponto de equilíbrio financeiro de uma empresa, momento em que despesas e receitas passam a equivaler.

Business Partner: é um parceiro de negócios na área de GP que gerencia, define, alinha e implementa alternativas para pessoas com foco no negócio.

CEO: Chief Executive Officer, ou Diretor Executivo, é o principal executivo de uma empresa.

Day off: comumente utilizado para especificar um dia de folga no dia de aniversário do colaborador.

Ecossistema: termo adotado a partir do conceito aplicado na biologia, considera que um ecossistema é formado pelo conjunto de comunidades e que interage entre si, construindo um ambiente estável, equilibrado e autossuficiente. São atores de um ecossistema de startup. Head: o termo em inglês foi apropriado pelo ambiente de negócios e indica líderes de áreas, ou seja, profissional de mais alta patente naquela estrutura, mesmo que seja uma posição de coordenação, gerência ou diretoria.

Home Office: trabalho de casa ou teletrabalho.

Lockdown: é a versão mais rígida do distanciamento social e quando a recomendação se torna obrigatória. É uma imposição do Estado que significa bloqueio total.

Modus operandi: termo com origem no latim respectivo a forma de operar.

NPS (Net Promoter Score): é uma metodologia desenvolvida pela Bain \& Company que mede a satisfação dos clientes, internos ou externos. Também tem sido utilizada para a avaliação de satisfação de colaboradores pela área de GP.

Slack: é uma ferramenta de colaboração online, que utilizada entre equipes, otimiza o processo de comunicação.

Tração: termo específico do ciclo de vida de uma startup, quando a empresa recebe aporte financeiro de um investidor.

Venture Capital: é um tipo de fundo de investimento focado em capital de crescimento para empresas de médio porte que possuem carteira de clientes e receita, mas que ainda precisam dar um salto de crescimento.

8 APÊNDICE A - Análise dos Resultados da Pesquisa do NPS

A partir dos comentários realizados no NPS pelos colaboradores, apresenta-se o relatório abaixo:

1. Você está satisfeito com sua saúde mental?

Alguns colaboradores se queixam de sintomas relacionados à ansiedade como dores de cabeça, insônia e palpitações. Em outros casos, o desânimo e a dificuldade em iniciar a rotina do dia de trabalho. Preocupações quanto à capacidade de serem produtivos e entregarem trabalhos de qualidade também chegaram a ser pontuados pelos colaboradores. 
2. Você está satisfeito com sua saúde física?

Algumas reclamações como dores nas costas, quadris e pernas foram pontuações constantes dos colaboradores. Outros se queixaram de inchaço nas pernas e mãos. Em casos menos recorrentes, foram identificadas queixas de incômodos nos ombros e punhos. Percebese nos relatos que os colaboradores têm uma menor mobilidade física, chegando a ficar sentados na mesma posição por muitas horas consecutivas.

3. Você percebe que estamos mantendo nossa essência da cultura de celebração?

Apesar de perceberem os esforços de seus líderes em manter a equipe atualizada, percebem que as celebrações têm sido realizadas de forma muito mais tímidas do que faziam antes. Muitos colaboradores apontaram sentirem falta de eventos como happy hour e celebrações de aniversário.

4. O quanto você está interagindo com seus colegas no dia a dia se comparado ao trabalho presencial?

Os relatos são de que os colaboradores passam muitas horas conectados com colegas e clientes, porém com discussões bastante técnicas e objetivas, o que chega a ser cansativo na interação online. A falta do contato com pessoas diferentes, tanto no ambiente laboral quanto fora, também chegaram a ser relatadas.

5. Você acredita que a empresa oferece condições para você realizar seu trabalho de forma adequada em home office?

Grande parte dos colaboradores se sente bem assistido pelos líderes de área, inclusive no entendimento quanto aos afazeres domésticos para quem tem filhos em casa. Porém, desconfortos com a conexão de internet, muitas vezes intermitente, é uma constante. A dificuldade em ajustarem a adequação de seu mobiliário, principalmente adequando as cadeiras em mesas que já possuíam em casa se reflete nas queixas físicas dos colaboradores.

\section{NOTAS DE ENSINO}

\subsection{OBJETIVOS EDUCACIONAIS}

O presente caso tem por finalidade permitir aos alunos vivenciar o desafio de compreender e analisar informações disponíveis em tempos de crise e incertezas, apresentado em um cenário dinâmico de mudanças constantes no contexto de uma empresa startup. A proposta é fazer com que os alunos analisem os dados apresentados e se coloquem no lugar de Caterine, discutindo e propondo formas de coletar, compreender e analisar informações, em um cenário de crise e incertezas, com o objetivo de planejar ações na área de Gestão de Pessoas para a empresa XPTO, através de soluções para o dilema proposto. São apresentados ao longo do caso termos em inglês, frequentemente utilizados no âmbito corporativo principalmente em startups, todos eles explicados através de um Glossário de Termos disponibilizados ao final da apresentação do caso, o que também auxilia no processo de aprendizagem do aluno.

O caso foi desenvolvido para: a) abordar a Teoria Contingencial, a qual enfatiza não existirem princípios ou regras universais, pois cada situação deve ser compreendida e analisada como única e aplicável a um determinado contexto e necessidades específicas; $b$ ) auxiliar os líderes no processo de tomada de decisão em cenários de incerteza, utilizando a 
ferramenta "POP-DOC Loop" que incorpora fatores humanos críticos, orienta a coleta e análise de dados dos líderes em direção a uma progressão lógica de decisões, ações e comunicações.

\subsection{UTILIZAÇÃO RECOMENDADA}

Recomenda-se a utilização deste caso para ensino no curso de Graduação em Administração nas disciplinas de Teoria Geral da Administração (foco na Teoria Contingencial), Gestão de Pessoas (Foco no Planejamento de ações em momentos de crise com auxílio da ferramenta "POP-DOC Loop"), Liderança (tomada de decisão em momentos de crise com auxílio da ferramenta "POP-DOC Loop"), e Estratégia Empresarial (utilização da ferramenta "POP-DOC Loop" para análise da situação em épocas de crise).

\subsection{FONTE DE DADOS}

Este caso para ensino é baseado em fatos reais e para sua construção foram utilizados dados coletados por meio de duas entrevistas online, semiestruturadas, com o Head of People da empresa. O nome da startup, local de atuação e os personagens foram alterados para preservar a identidade dos envolvidos e da empresa. Além disso, foi necessária a criação de elementos e diálogos de modo a enriquecer a redação do caso e proporcionar mais elementos para uma melhor reflexão por parte dos estudantes.

\subsection{PLANO DE ENSINO}

O caso para ensino apresentado pode suportar os seguintes objetivos de aprendizagem:

a) Compreender que cada situação deve ser entendida e analisada como única e aplicável a um determinado contexto e necessidades específicas;

b) Analisar informações disponíveis em cenários de crise e incertezas;

c) Propor em cenários de crise e incertezas uma progressão lógica de decisões, ações e comunicações.

Para utilização deste caso em sala de aula o docente pode optar por um dos seguintes caminhos: i) escolher aplicar o caso para trabalhar a Teoria Contingencial, trabalhando os objetivos de aprendizagem "Compreender que cada situação deve ser entendida e analisada como única e aplicável a um determinado contexto e necessidades específicas" e "Analisar informações disponíveis em cenários de crise e incertezas"; ii) trabalhar o Modelo POP-DOC Loop com foco nos objetivos de aprendizagem "Analisar informações disponíveis em cenários de crise e incertezas" e "Propor em cenários de crise e incertezas uma progressão lógica de decisões, ações e comunicações"; iii) Trabalhar tanto a Teoria Contingencial quanto o Modelo POP-DOC Loop conjuntamente, mas para isso seriam necessárias aproximadamente 5 horas aula. Aqui serão apresentados os Planos de Aula para suportar os dois primeiros caminhos propostos, pois acredita-se que o terceiro pode ser estruturado e adaptado pelo docente com base nos seus objetivos de ensino.

Quanto a sua aplicação, sugere-se que o caso, juntamente com o Glossário de Termos e o Apêndice A, sejam disponibilizados uma semana antes da aplicação dos mesmos pelo docente em sala de aula, para que os alunos possam realizar uma leitura prévia do material e se familiarizarem com a narrativa e com os termos corporativos nele apresentados. Propõese que o docente, antes de trabalhar o caso com seus alunos, aborde em sala de aula o conteúdo relacionado a Teoria Contingencial ou Modelo POP-DOC Loop, explanados brevemente neste material na seção Teoria e Modelo, em no máximo 30 minutos. 
Ambos os planos de aula apresentados utilizam a escala de Leenders e Erskine (1989) que aborda os três diferentes níveis de dificuldades presentes no caso para ensino: 1 Apresentação, representa um nível de complexidade fácil; 2 - Conceitual, nível de complexidade médio; 3 - Analítica, nível de complexidade difícil.

No Quadro 1 são apresentadas as atividades sugeridas para trabalhar a Teoria Contingencial com base no caso proposto, seguidas dos seus respectivos níveis de complexidade, objetivo educacional e tempo de aplicação sugerido. Sugere-se a utilização das questões sugeridas sobre Teoria Contingencial, no material que compõem as Notas de Ensino, como forma de suportar as últimas 4 atividades propostas no Quadro 1.

Quadro 1 - Sugestão de plano de aula para trabalhar a teoria contingencial

\begin{tabular}{|c|c|c|c|}
\hline Atividades & $\begin{array}{c}\text { Nível de } \\
\text { Complexidade }\end{array}$ & Objetivo Educacional & $\begin{array}{c}\text { Tempo } \\
\text { Sugerido }\end{array}$ \\
\hline 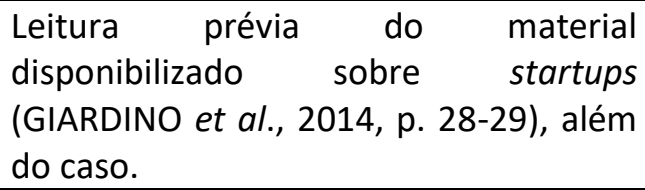 & $\begin{array}{c}1- \\
\text { Apresentação }\end{array}$ & $\begin{array}{l}\text { Entender o que é uma } \\
\text { startup e suas principais } \\
\text { características }\end{array}$ & $0 \mathrm{~min}$. \\
\hline $\begin{array}{l}\text { Apresentar a Teoria Contingencial (nível } \\
\text { de aprofundamento definido pelo } \\
\text { professor conforme objetivos de } \\
\text { aprendizagem da disciplina) }\end{array}$ & $\begin{array}{c}1- \\
\text { Apresentação }\end{array}$ & $\begin{array}{l}\text { Compreender a } \text { Teoria } \\
\text { contingencial e } \text { suas } \\
\text { principais características }\end{array}$ & $40 \mathrm{~min}$. \\
\hline $\begin{array}{l}\text { Dividir os alunos em grupos ( } 3 \text { a } 5 \\
\text { alunos) para trabalharem o conceito de } \\
\text { startup e suas características }\end{array}$ & 2 -Conceitual & $\begin{array}{l}\text { Entender o que é uma } \\
\text { startup e identificar quais } \\
\text { as características deste } \\
\text { tipo de empresa presentes } \\
\text { na XPTO }\end{array}$ & $30 \mathrm{mim}$. \\
\hline $\begin{array}{l}\text { Promover uma discussão em grande } \\
\text { grupo sobre as características da XPTO } \\
\text { como startup e quais os contextos e } \\
\text { necessidades são inerentes a este tipo } \\
\text { de empresa em um contexto sem } \\
\text { grandes crises e incertezas }\end{array}$ & 3-Analítica & $\begin{array}{l}\text { Discutir sobre } \\
\text { características de uma } \\
\text { startup e como o contexto } \\
\text { e suas necessidades } \\
\text { podem afetá-las }\end{array}$ & $40 \mathrm{~min}$. \\
\hline $\begin{array}{l}\text { Identificar, novamente em grupos, os } \\
\text { elementos do ambiente externo que } \\
\text { podem ser riscos ou oportunidades para } \\
\text { XPTO no contexto do caso apresentado }\end{array}$ & 2 -Conceitual & $\begin{array}{l}\text { Identificar elementos do } \\
\text { ambiente externo que } \\
\text { podem ser fontes de risco } \\
\text { ou oportunidade }\end{array}$ & $30 \mathrm{~min}$. \\
\hline $\begin{array}{l}\text { Promover uma discussão em grande } \\
\text { grupo sobre os riscos e oportunidades } \\
\text { que a XPTO pode encontrar no seu } \\
\text { ambiente de acordo com o caso } \\
\text { apresentado }\end{array}$ & 3-Analítica & $\begin{array}{l}\text { Listar os riscos e } \\
\text { oportunidades relatados } \\
\text { pelos grupos e montar um } \\
\text { quadro com aqueles que a } \\
\text { turma entender serem os } \\
\text { mais importantes para a } \\
\text { XPTO investir seus } \\
\text { esforços }\end{array}$ & $40 \min$ \\
\hline
\end{tabular}

Fonte: elaborado pelos autores (2020).

Para trabalhar o Modelo POP-DOC Loop sugere-se o seguinte Plano de Aula com as atividades e seus respectivos níveis de complexidade, objetivo educacional e tempo de aplicação sugerido, conforme Quadro 2. Sugere-se utilizar como ferramenta de suporte para as atividades propostas as questões sugeridas para o Modelo POD-DOC Loop no material que compõem as Notas de Ensino. 
Renata Freire De Almeida, Luiz Henrique Da Silva, Tatiana Ghedine e Anete Alberton

Quadro 2 - Sugestão de plano de aula para trabalhar o modelo POP-DOC Loop

\begin{tabular}{|l|c|c|c|}
\hline \multicolumn{1}{|c|}{ Atividades } & \multicolumn{1}{|c|}{$\begin{array}{c}\text { Nível de } \\
\text { Complexidade }\end{array}$} & \multicolumn{1}{c|}{ Objetivo Educacional } & $\begin{array}{c}\text { Tempo } \\
\text { Sugerido }\end{array}$ \\
\hline Apresentar o Modelo POP-DOC Loop & 1-Apresentação & Conhecer o modelo e suas etapas & 30 min. \\
\hline $\begin{array}{l}\text { Dividir os alunos em grupos (3 a 5 alunos) } \\
\text { para que identifiquem os principais } \\
\text { desafios e dificuldades enfrentados pela } \\
\text { XPTO }\end{array}$ & 2 -Conceitual & $\begin{array}{l}\text { Discutir o processo de } \\
\text { levantamento de informações e } \\
\text { tomada de decisão }\end{array}$ & 20 mim. \\
\hline $\begin{array}{l}\text { Identificar as análises e ações realizadas } \\
\text { pelos líderes da XPTO relacionadas a } \\
\text { cada uma das seis etapas do modelo } \\
\text { POP-DOC Loop }\end{array}$ & 2-Conceitual & $\begin{array}{l}\text { Discutir sobre as etapas do } \\
\text { Modelo POP-DOC Loop }\end{array}$ & 30 min. \\
\hline $\begin{array}{l}\text { Estimular os alunos a refletirem sobre a } \\
\text { atuação dos líderes em tempos de crise e } \\
\text { incertezas }\end{array}$ & 2-Conceitual & $\begin{array}{l}\text { Avaliar a relevância da atuação } \\
\text { dos líderes em tempos de crise e } \\
\text { incertezas }\end{array}$ & 30 min. \\
\hline $\begin{array}{l}\text { Solicitar aos grupos que elaborem ações } \\
\text { a serem implementadas pela área de GP } \\
\text { o contexto de home office e a crise } \\
\text { pandêmica }\end{array}$ & 3-Analítica & $\begin{array}{l}\text { Avaliar os resultados do NPS } \\
\text { sugerindo ações para o contexto } \\
\text { de home office e a crise } \\
\text { pandêmica }\end{array}$ & 30 min \\
\hline $\begin{array}{l}\text { Promover uma discussão em grande } \\
\text { grupo sobre os possíveis planos de ação } \\
\text { a serem implementados }\end{array}$ & 3-Analítica & $\begin{array}{l}\text { Avaliar as ações mais viáveis } \\
\text { sugeridas montando um modelo } \\
\text { único de ação para a XPTO }\end{array}$ & 40 min \\
\hline
\end{tabular}

Fonte: elaborado pelos autores (2020).

\section{TEORIA E MODELO}

Este caso é analisado pela lente da Teoria Contingencial e pelo Modelo POP-DOC Loop, ao qual são apresentados na sequência.

\subsection{TEORIA CONTINGENCIAL}

A Teoria Contingencial se originou a partir da análise das estruturas da organização e da sua interação com o ambiente externo (AFFONSO; FERRARI, 2018). Ela parte do princípio que não existe uma estrutura ou prática administrativa única, uma maneira única de se organizar uma empresa para atingir os objetivos propostos. Considera que dependendo do tipo de ambiente, do objetivo ou problema a ser solucionado, vários tipos de organização são possíveis, e é preciso observar as características específicas ou a contingência de cada situação concreta (MOTTA; VASCONCELOS, 2006).

Essa teoria apresenta a cognição como função entre empresa e ambiente, contribuindo para o controle e redução da incerteza ambiental (NOBRE; TOBIAS; WALKER, 2011). As organizações constroem uma representação do ambiente, e em seguida, utilizam essa representação para tomada de decisão (CSASZAR; OSTLER, 2020). Na perspectiva de liderança, a ênfase da abordagem contingencial incide sobre a capacidade de adaptação do líder a diferentes situações. A liderança é contingencial e compete ao líder adaptar suas características às demandas coletivas ou situacionais, ou seja, não existe um estilo de liderança único, o líder precisa ajustar seu comportamento com base em uma compreensão da situação e assumir um estilo de liderança adequado para a ocasião (TOLFO, 2010). 
De repente tudo mudou: liderando em tempos de crise

\subsection{MODELO POP-DOC LOOP}

O modelo POP-DOC Loop foi desenvolvido pela Iniciativa Nacional de Preparação em Liderança, um programa de treinamento e pesquisa para liderança em crises da Universidade de Harvard (MARCUS et al., 2014). Este modelo demonstra uma estrutura para fornecer uma orientação sistemática para aquisição de uma consciência situacional, ou seja, para a capacidade de identificar, processar e compreender as situações críticas sobre um acontecimento imprevisto. Esta ferramenta foi utilizada por líderes em situação de crise, como por exemplo, na crise de H1N1 em 2009, onde permitiu uma sequência rápida de análise e ação, à medida que as informações eram filtradas, e no furacão Sandy em 2012, para prestar assistência de emergência, moradia e suprimentos (MARCUS et al., 2020).

O POP-DOC Loop incorpora fatores humanos críticos, orientando a coleta e análise de dados do líder em direção a uma progressão lógica de decisões, ações e comunicações, permitindo-o operar em situações voláteis, incertas, complexas e ambíguas. Nessas situações há muitos fatores conhecidos, porém, há muito mais fatores desconhecidos, cabendo ao líder investigar e analisar essas incógnitas que não estão acessíveis. No entanto, uma situação de crise requer uma rápida conscientização situacional e tomadas de decisões oportunas (MARCUS et al., 2020).

No Quadro 3 são abordadas a descrição de cada uma das etapas do POP-DOC Loop.

Quadro 3 - Etapas do POP-DOC Loop

\begin{tabular}{|c|c|}
\hline Etapa & Descrição \\
\hline Perceber & $\begin{array}{l}\text { Desenvolver a conscientização de uma situação de engajamento ativo nas realidades do } \\
\text { ambiente externo e seu impacto na organização. Nessa etapa é preciso abrir a mente para } \\
\text { reunir o máximo de dados possível, se alertando de que algumas informações podem estar } \\
\text { corretas e outras apenas especulações, sendo necessário filtrá-las. O líder precisa ficar atento } \\
\text { à algumas distrações, como as emoções e atenção à crise. A percepção precisa é a chave para } \\
\text { percorrer com êxito as próximas etapas do modelo. }\end{array}$ \\
\hline Orientar & $\begin{array}{l}\text { Montagem das informações em padrões, separando dados relevantes dos irrelevantes. Esses } \\
\text { padrões são determinados pelo líder e fornecem um entendimento simples e orientam as } \\
\text { ações subsequentes. Essa etapa situa o que está acontecendo e o que precisa ser feito em um } \\
\text { contexto maior. As mudanças no ambiente podem levar a mudanças desses padrões. }\end{array}$ \\
\hline Prever & $\begin{array}{l}\text { Alerta padrões que predizem a progressão da situação e o potencial impacto das intervenções. } \\
\text { Orienta os líderes à medida que antecipam e se preparam para atuar sobre o que } \\
\text { provavelmente acontecerá a seguir. Essas previsões fornecem um guia que se ajusta á medida } \\
\text { que novas informações se tornam disponíveis. Essa etapa é mais bem estruturada quando } \\
\text { líderes coletam informações de outras partes interessadas e membros da equipe, por meio } \\
\text { de um processo de socialização. }\end{array}$ \\
\hline Decidir & $\begin{array}{l}\text { É considerado o compromisso com o curso da ação, é a transição da análise para ação. Com } \\
\text { base nas previsões, um caminho a seguir precisa ser escolhido. Fazer isso no momento correto } \\
\text { e com apoio adequado, é uma importante decisão do líder. O modelo informa e solicita a } \\
\text { tomada de decisão necessária para catalisar a ação. }\end{array}$ \\
\hline Operacionalizar & $\begin{array}{l}\text { Essa etapa socializa e ativa as decisões da etapa anterior. Operacionalizar as decisões requer } \\
\text { uma compreensão do que é necessário para mover os sistemas e as consequências que } \\
\text { resultarão. Para que as decisões sejam traduzidas em movimento, uma parte diferente do } \\
\text { cérebro é ativada para calibrar os recursos, atividades e suporte necessário para atingir o } \\
\text { objetivo. }\end{array}$ \\
\hline Comunicar & $\begin{array}{l}\text { Define o fluxo de informações que saem para as pessoas, bem como, informações que podem } \\
\text { ser utilizadas para iniciar o processo novamente. As decisões e ações devem ser amplamente } \\
\text { divulgadas, para que as partes interessadas saibam o que está acontecendo e o que precisam } \\
\text { fazer. Com o feedback, se volta para avaliar o impacto e o resultado. É fundamental para cada } \\
\text { etapa do modelo, enfatiza a etapa final do processo, iniciando a próxima rodada. }\end{array}$ \\
\hline
\end{tabular}

Fonte: Marcus et al. (2014); Marcus et al. (2015); Marcus et al. (2020). 
Essa ferramenta pode fornecer aos líderes uma estrutura para identificar e abordar rapidamente consequências não intencionais ou negativas de suas análises, decisões e ações (MARCUS et al., 2020). A Figura 1 ilustra a dinâmica do modelo proposto.

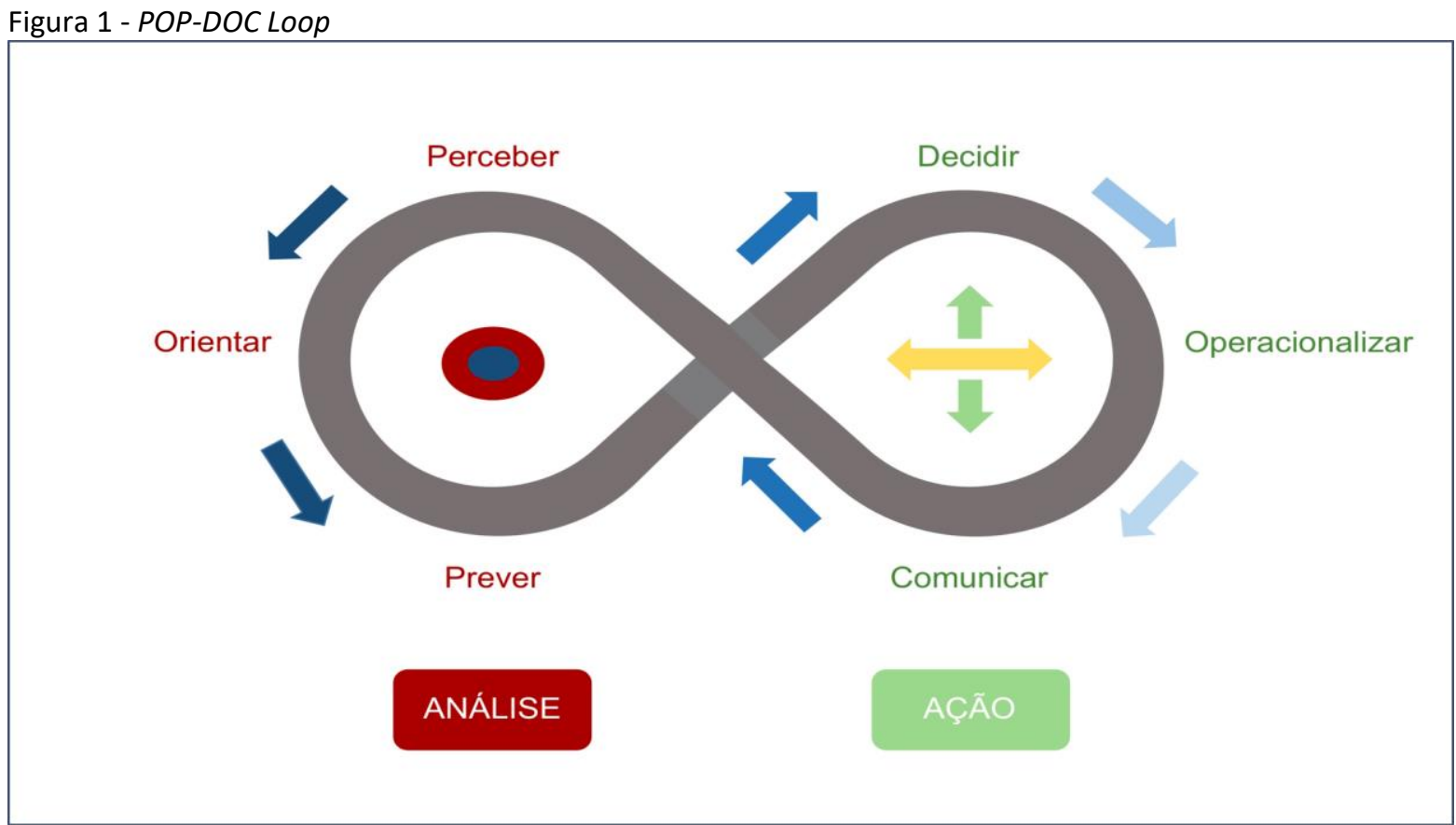

Fonte: adaptado de Marcus et al. (2015).

Observa-se na Figura 1 as seis etapas apresentadas anteriormente (quadro 3), divididas em etapas de análise (perceber, orientar e prever) e etapas de ação (decidir, operacionalizar e comunicar), essa aquisição de consciência situacional por meio do modelo é geralmente um processo repetitivo e contínuo, com avaliações e ajustes frequentes. (MARCUS et al., 2020). Uma vez aplicado o POP-DOC Loop o líder reinicia o caminho, percebendo os impactos do que foi realizado, orientando novos padrões, prevendo como as mudanças se manifestarão, tomando novas decisões, operacionalizando um curso de ação ajustado, e posteriormente, comunicando novas diretrizes e resultados (MARCUS et al., 2014). À medida que mais informações surgem, a compreensão da situação aumenta, e com isso, as opções mudam, requerendo uma nova análise. Assim, o modelo pode e deve atravessado várias vezes à medida que a situação se desenrola (MARCUS et al., 2015).

\section{SUGESTÃO DE QUESTÕES PARA DISCUSSÃO SOBRE TEORIA CONTINGENCIAL}

1. De acordo com a Teoria Contingencial cada situação deve ser entendida e analisada como única e aplicável a um determinado contexto e necessidades específicas. Diante disso, torna-se importante entender o que é uma startup e quais características deste tipo de empresa estão presentes na XPTO?

2. A Teoria Contingencial aborda que existe relação entre as variáveis externas e as características organizacionais. Desta forma, são as condições do ambiente que causam transformações no interior das organizações. Analisando o caso apresentado, retrate quais elementos do ambiente externo são ou podem constituir oportunidades ou ameaças para XPTO? 


\section{SUGESTÃO DE QUESTÕES PARA DISCUSSÃO SOBRE MODELO POP-DOC LOOP}

1. Com base no modelo POP-DOC Loop apresentado, identificar as análises e ações realizadas por Caterine ou por outros líderes da XPTO relacionadas a cada uma das seis etapas do modelo. ATENÇÃO: foram realizadas duas rodadas de atuação, a rodada 1 (capítulos "Introdução" e "COVID-19, Lockdown e Home Office") e rodada 2 (capítulo "Mudança de planos"). Cada uma delas deve ser apresentada separadamente.

2. Evidencie como cada etapa do modelo POP-DOC Loop foi relevante para atuação dos líderes no cenário de pandemia retratado na XPTO.

3. Analise os resultados do NPS realizado por Caterine (Apêndice A) e elabore ações a serem implementadas pela área de GP, considerando o contexto de home office e a crise pandêmica.

\section{ANÁLISE DO CASO COM SUPORTE DA LITERATURA SOBRE A TEORIA CONTINGENCIAL}

1. De acordo com a Teoria Contingencial cada situação deve ser entendida e analisada como única e aplicável a um determinado contexto e necessidades específicas. Diante disso, torna-se importante entender o que é uma startup e quais características deste tipo de empresa estão presentes na XPTO?

Startup é uma empresa nova, até mesmo incipiente ou em processo de constituição, abrangendo projetos promissores, relacionados a pesquisa, investigação e desenvolvimento de ideias inovadoras (SEBRAE, 2020). Elas são consideradas empresas ágeis com capacidade dinâmica de adaptar-se às mudanças no ambiente de negócios (OLIVA; KOTABE, 2019). São compostas por um grupo de pessoas que procuram por um modelo de negócios inovador, repetível e escalável, trabalhando em condições de incerteza. Por se tratar de uma economia pautada no conhecimento seu maior insumo são boas ideias (MORAES, 2020).

As principais características de uma startup estão descritas no Quadro 4.

Quadro 4 - Características das startups

\begin{tabular}{|l|l|l|}
\hline Características & \multicolumn{1}{|c|}{ Descrição } & \multicolumn{1}{|c|}{ XPTO } \\
\hline Falta de recursos & $\begin{array}{l}\text { Recursos econômicos, humanos e físicos são } \\
\text { extremamente limitados. }\end{array}$ & $\begin{array}{l}\text { Fundada através de um reduzido } \\
\text { recurso financeiro. }\end{array}$ \\
\hline Altamente reativo & $\begin{array}{l}\text { As startups podem reagir rapidamente às } \\
\text { mudanças no mercado, tecnologias e produtos } \\
\text { subjacentes (em comparação com empresas } \\
\text { mais estabelecidas). }\end{array}$ & $\begin{array}{l}\text { O ritmo da empresa requer } \\
\text { adaptabilidade. }\end{array}$ \\
\hline Inovação & $\begin{array}{l}\text { Dado o ecossistema altamente competitivo, as } \\
\text { startups precisam se concentrar e explorar } \\
\text { segmentos altamente inovadores do mercado. }\end{array}$ & $\begin{array}{l}\text { Atua no mercado de tecnologia da } \\
\text { informação (TI), um segmento de } \\
\text { constante inovação. }\end{array}$ \\
\hline Incerteza & $\begin{array}{l}\text { As startups lidam com um ecossistema } \\
\text { altamente incerto sob diferentes perspectivas: } \\
\text { mercados, recursos do produto, concorrência, } \\
\text { pessoas e finanças. }\end{array}$ & $\begin{array}{l}\text { Os gestores da XPTO atuam em um } \\
\text { ecossistema incerto, lidando sob } \\
\text { diferentes perspectivas, sejam elas, o } \\
\text { mercado, produtos ou pessoas. }\end{array}$ \\
\hline $\begin{array}{l}\text { Em rápida } \\
\text { evolução }\end{array}$ & $\begin{array}{l}\text { As startups de sucesso buscam crescer e escalar } \\
\text { rapidamente. }\end{array}$ & $\begin{array}{l}\text { Tem como propósito "Queimar o } \\
\text { caixa rápido para crescermos rápido", } \\
\text { seja, a promoção } \\
\text { da } \\
\text { escalabilidade. }\end{array}$ \\
\hline
\end{tabular}


Renata Freire De Almeida, Luiz Henrique Da Silva, Tatiana Ghedine e Anete Alberton

\begin{tabular}{|c|c|c|}
\hline Pressão do tempo & $\begin{array}{l}\text { O ambiente geralmente força as startups a } \\
\text { liberar-se rapidamente e a trabalhar sob } \\
\text { constante pressão. }\end{array}$ & $\begin{array}{l}\text { Os gestores trabalham sob constante } \\
\text { pressão e necessitam agir } \\
\text { rapidamente. }\end{array}$ \\
\hline Equipe pequena & $\begin{array}{l}\text { As startups começam com um pequeno número } \\
\text { de indivíduos. }\end{array}$ & $\begin{array}{l}\text { Fundada com uma pequena equipe de } \\
\text { trabalho. }\end{array}$ \\
\hline Um & $\begin{array}{l}\text { As atividades da empresa gravitam em torno de } \\
\text { apenas um produto/serviço. }\end{array}$ & $\begin{array}{l}\text { Oferece como serviço o SaaS, uma } \\
\text { plataforma de gestão de atendimento } \\
\text { a clientes. }\end{array}$ \\
\hline $\begin{array}{l}\text { Equipe com p } \\
\text { experiência }\end{array}$ & $\begin{array}{l}\text { Boa parte da equipe de desenvolvimento é } \\
\text { formada por pessoas com menos de cinco anos } \\
\text { de experiência e frequentemente estudantes } \\
\text { recém-formados. }\end{array}$ & $\begin{array}{l}\text { Conta com } 150 \text { colaboradores no seu } \\
\text { quadro de pessoal, em sua grande } \\
\text { maioria recém-formados ou com } \\
\text { pouca experiência de mercado. }\end{array}$ \\
\hline & foi criada recentemente. & $\mathrm{da} \mathrm{em} 2$ \\
\hline $\begin{array}{l}\text { Não } \\
\text { autossustentáveis }\end{array}$ & $\begin{array}{l}\text { Especialmente no estágio inicial, as startups } \\
\text { precisam de financiamento externo para } \\
\text { sustentar suas atividades (capital de risco, } \\
\text { investidores anjos, fundos e assim por diante). }\end{array}$ & $\begin{array}{l}\text { Recebeu aporte financeiro de uma } \\
\text { Venture Capital em setembro de } \\
2019 .\end{array}$ \\
\hline $\begin{array}{l}\text { Pouca experiê } \\
\text { de trabalho }\end{array}$ & $\begin{array}{l}\text { A base de uma cultura organizacional não está } \\
\text { presente inicialmente. }\end{array}$ & $\begin{array}{l}\text { Caterine propõe a ação de mapear a } \\
\text { cultura organizacional, que não tinha } \\
\text { uma base clara inicialmente na XРTO. }\end{array}$ \\
\hline
\end{tabular}

Fonte: adaptado de Giardino et al., (2014, p. 28-29).

2. A Teoria Contingencial aborda que existe relação entre as variáveis externas e as características organizacionais. Desta forma, são as condições do ambiente que causam transformações no interior das organizações. Analisando o caso apresentado, retrate quais elementos do ambiente externo são ou podem constituir oportunidades ou ameaças para XPTO?

O ambiente de incerteza ocasionado pela COVID-19, torna a análise de oportunidades e ameaças um tanto quanto imprecisos, dada a velocidade imprevisibilidade dos acontecimentos externos. Um diagnóstico rápido e preciso para a tomada de decisão igualmente assertiva acaba sendo vital para a manutenção das empresas e negócios.

A oportunidade é considerada uma situação externa, fora do domínio direto da organização, é o que o ambiente externo oferece para os competidores, podendo contribuir, se for adequadamente aproveitada, com o alcance dos objetivos e melhoria do desempenho do negócio (FERNANDES, 2012). A ameaça também está presente fora do domínio direto organizacional, podendo causar sérios danos caso se interponha no caminho escolhido. Tem o potencial de prejudicar o desempenho da organização se não for repelida, e pode surgir de pontos fortes dos competidores, do ambiente institucional ou de alterações radicais no negócio (FERNANDES, 2012). A seguir, são apresentadas as oportunidades e ameaçadas presentes no caso retratado:

a) Oportunidades do ambiente externo:

Home Office: o projeto de home office, que estava na agenda de GP, acabou sendo implantado. Com isso, a oportunidade já levantada pelos colaboradores anteriormente de poderem trabalhar de outras cidades, por exemplo, torna-se realidade.

Digitalização: há a possibilidade de aumentar as vendas da empresa, considerando que se trata de um serviço digital e o potencial de que as pessoas sob novas condições de relação no ambiente digital, façam contratações destes serviços.

Benchmarking: empresas mais propensas a trocas e benchmarkings para que pudessem, com velocidade, adaptar suas práticas. 


\section{b) Ameaças do ambiente externo:}

Fake News: dada a incerteza no cenário de constantes mudanças, as notícias falsas se espalham com bastante velocidade, gerando desgaste das pessoas e do ambiente organizacional a partir de informações imprecisas.

Absenteísmo: existe a possibilidade de que os colaboradores se contaminem com a COVID-19, ocasionando, no mínimo, o absenteísmo de colaboradores ou, em casos mais graves, sua perda.

Vendas retraídas: em um negócio de alta velocidade como uma startup, o não cumprimento de metas de vendas pode ser fatal para a sustentabilidade do negócio e retorno financeiro aos investidores.

\section{ANÁLISE DO CASO COM SUPORTE DA LITERATURA SOBRE O MODELO POP-DOC LOOP}

1. Com base no modelo POP-DOC Loop apresentado, identifique as análises e ações realizadas por Caterine ou por outros líderes da XPTO em cada uma das seis etapas do modelo. Lembrase que foram realizadas duas rodadas de atuação, a rodada 1 (capítulos "Introdução" e "COVID-19, Lockdown e Home Office") e rodada 2 (capítulo "Mudança de planos"), devendo apresentá-las separadamente.

No discurso e atitudes dos personagens, é possível identificar os momentos em que as 6 etapas do modelo POP-DOC Loop são realizadas. Este modelo é fundamentado em etapas e atividades previamente identificadas, e as coloca em uma sequência adaptativa contínua de processos repetitivos, que são avaliados ou ajustados frequentemente, ou seja, as etapas podem se repetir e o líder deve ajustá-las incorporando novas informações sobre o cenário. Este processo de melhoria contínua colabora para que os líderes alcancem o melhor resultado possível em uma crise (MARCUS et al., 2020).

Nos Quadros 5 e 6, estão exemplificados os ciclos do modelo realizados em duas rodadas de atuação. $O$ Quadro 5 apresenta as principais análises e ações realizadas por Caterine e demais líderes da XPTO, na primeira rodada do modelo, expostas nos capítulos "Introdução" e "COVID-19, Lockdown e Home Office".

Quadro 5 - Análises e ações da primeira rodada

\begin{tabular}{|l|l|}
\hline \multicolumn{2}{|l|}{ Rodada 1 } \\
\hline Etapas & Análises/Ações \\
\hline Perceber & $\begin{array}{l}\text { 1. O CEO Sérgio marca uma reunião com os heads de área no dia } 12 \text { março } \\
\text { percebendo as notícias sobre a pandemia no Brasil e no mundo a respeito dos } \\
\text { casos da COVID-19. }\end{array}$ \\
\hline Orientar & $\begin{array}{l}\text { 2. Caterine propõe realizar um plano de ação, recebendo aprovação do CEO para } \\
\text { elaborá-lo. }\end{array}$ \\
\hline Decidir & $\begin{array}{l}\text { 3. Caterine busca informações sobre a pandemia para elaborar seu plano de ação, } \\
\text { prevendo que o cenário pandêmico levaria os colaboradores ao home office. }\end{array}$ \\
\hline Operacionalizar & $\begin{array}{l}\text { 4. O plano de ação foi prontamente aprovado pelo CEO e outros líderes no dia 13 } \\
\text { de março de 2020. Nesse plano de ação foi decidido que 20\% dos colaboradores } \\
\text { de cada equipe trabalhariam em home office. }\end{array}$ \\
\hline $\begin{array}{l}\text { 5. Caterine e os heads da área tiveram que organizar os processos de suas áreas e } \\
\text { decidir quem seriam os colaboradores que trabalhariam em home office a partir }\end{array}$ \\
\hline
\end{tabular}


Renata Freire De Almeida, Luiz Henrique Da Silva, Tatiana Ghedine e Anete Alberton

\begin{tabular}{|l|l|}
\hline \multirow{3}{*}{ Comunicar } & $\begin{array}{l}\text { 6. Em 13 de março de 2020, os heads de área comunicaram suas equipes e } \\
\text { conversaram individualmente com os colaboradores que trabalhariam em home } \\
\text { office; } \\
\text { 7. Caterine centralizou a comunicação na área de GP emitindo um comunicado a } \\
\text { todos os colaboradores da empresa utilizando as ferramentas de e-mail e slack. }\end{array}$ \\
\hline
\end{tabular}

Fonte: elaborado pelos autores (2020).

O Quadro 6 demonstra as principais análises e ações realizadas por Caterine e demais líderes da XPTO, na segunda rodada do modelo, expostas no capítulo "Mudança de planos".

Quadro 6 - Análises e ações da segunda rodada

\begin{tabular}{|l|l|}
\hline \multicolumn{2}{|c|}{ Rodada 2} \\
\hline Etapas & Análises/Ações \\
\hline Perceber & 1. Caterine com as notícias na mídia percebeu que a situação estava se agravando. \\
\hline Prientar & $\begin{array}{l}\text { 2. Caterine recomenda a formação de um comitê de crise com os heads de área para } \\
\text { compartilharem e orientarem as ações que seriam tomadas; } \\
\text { 3. Caterine sugeriu a realização de um benchmarking com as empresas do segmento. }\end{array}$ \\
\hline Decidir & $\begin{array}{l}\text { 4. Com o resultado do benchmarking e os indicativos do mercado, o comitê percebeu que a } \\
\text { situação poderia não ser segura para os colaboradores. }\end{array}$ \\
\hline $\begin{array}{l}\text { 5. Os líderes decidiram que a partir de 16 de março de 2020 100\% dos colaboradores } \\
\text { trabalhariam em home office; } \\
\text { 6. O comitê de crise estabeleceu uma única fonte de informação oficial a respeito da COVID- } \\
\text { 19; } \\
\text { 7. O comitê de crise decidiu por centralizar a comunicação na figura do CEO. }\end{array}$ \\
$\begin{array}{l}\text { 8. Operacionalização para o trabalho em home office pelo comitê de crise; } \\
\text { 9. O líder de TI ficou como responsável pela distribuição de equipamentos e softwares de } \\
\text { trabalho remoto; } \\
\text { 10. O líder de infraestrutura organizou a distribuição de cadeiras e mobiliário; } \\
\text { 11. O líder de marketing ficou responsável por elaborar a base de informações; } \\
\text { 12. Caterine e sua equipe ficaram responsáveis pela comunicação individual com cada um } \\
\text { dos 140 colaboradores. }\end{array}$ \\
\hline Comunicar & $\begin{array}{l}\text { 13. O CEO emitiu um comunicado oficial por e-mail e slack aos colaboradores sobre as } \\
\text { atividades laborais em home office e a divulgação do link para a base de informaçes. }\end{array}$ \\
\hline
\end{tabular}
Fonte: elaborado pelos autores (2020).

Nas duas rodadas observa-se que os cenários foram se modificando. No primeiro momento a situação de crise ainda estava iniciando e a empresa optou por se antecipar frente ao que poderia acontecer. No segundo momento, com o agravamento do cenário, Caterine e os demais líderes precisaram realizar novas ações para reduzir as incertezas e controlar a situação. Nesse sentido, MARCUS et al., (2020) aponta que avaliar a situação, o que está acontecendo e o que fazer a respeito, é um processo dinâmico e em constante mudança, que exige aos líderes tomadas de decisões arriscadas combinadas com resultados desconhecidos. Desta forma, quanto melhor o entendimento da situação e das pessoas afetadas neste processo, melhor será o alcance dos objetivos pretendidos.

2. Evidencie como cada etapa do modelo POP-DOC Loop foi relevante para atuação dos líderes no cenário de pandemia retratado na XPTO.

Perceber: ajudou Sérgio e Caterine a entender a situação da COVID-19, reconhecer o que estava acontecendo, absorver informações, avaliar dados e distinguir as informações relevantes das irrelevantes por meio das notícias na mídia sobre o Brasil e o mundo.

Orientar: permitiu que as informações detectadas e compreendidas por Caterine, fornecessem uma percepção mais rica da situação, como a proposta do plano de ação, criação do comitê de crise e realização do benchmarking, construindo uma compreensão dos padrões e avaliando o que esses padrões em andamento poderiam significar para organização.

RGO - Revista Gestão Organizacional, Chapecó, v. 14, n. 1, p. 450-469, jan./abr. 2021. 
Prever: possibilitou usar os padrões identificados para antecipar a trajetória dos eventos e gerar opções, permitindo eliminar contingências antes mesmo de serem executadas, prevendo o que provavelmente teria sucesso ou que falharia, como na situação do trabalho em home office percebido por Caterine e pelo comitê de crise.

Decidir: proporcionou construir, sobre o que era conhecido e de acordo com os resultados almejados, as melhores formas de executar o plano de ação, como a proposta de Caterine de $20 \%$ dos colaboradores em home office, ou as decisões realizadas pelo comitê de crise, como por exemplo: $100 \%$ de trabalho em home office, única fonte de informação oficial e a centralização da comunicação na figura do CEO.

Operacionalizar: colaborou com o envolvimento de relacionamentos e parcerias entre os heads de áreas para oferecer a melhor chance de gerar consequências positivas para as mudanças na XPTO, além de ter estabelecido conectividade entre os líderes para executar os processos e implementar recursos para realizar as decisões, como na mobilização individualmente de cada profissional de sua equipe.

Comunicar: propiciou que todas as partes interessadas soubessem o que estava acontecendo, como na emissão de comunicados aos colaboradores por e-mail e slack. A base de informações oficial divulgada pela XPTO, com notícias sobre Brasil e o mundo, também auxiliou na identificação de informações úteis para o acompanhamento da situação pandêmica.

3. Analise os resultados do NPS realizado por Caterine (Apêndice A) e elabore ações a serem implementadas pela área de GP, considerando o contexto de home office e a crise pandêmica.

A formulação de estratégias organizacionais é complexa, pelo fato de a própria estratégia estar mergulhada em uma multiplicidade de fatores e componentes internos e externos, que muitas vezes, estão situados fora do controle e previsão da organização (BARBOSA; BRONDANI, 2005). Portanto, é preciso antecipar situações futuras e se adaptar as condições do ambiente, para garantir a empresa o alcance de seus objetivos (ALMEIDA; OLIVEIRA, 2020).

Caterine se encontra em um momento de gerenciamento de crise, e $100 \%$ dos colaboradores da XPTO estão trabalhando em home office, dificultando seu trabalho, visto as ações realizadas pela área de GP serem remotas. Com base no relatório NPS, identificou-se quatro linhas de frente de trabalho a serem desenvolvidas como ações a partir das respostas dos colaboradores (Apêndice A), sendo elas: saúde mental, saúde física, integração dos colaboradores e estrutura.

As possíveis ações a serem realizadas em cada uma das quatros linhas de frente são:

1) Saúde mental: contratação de um psicólogo para apoiar emocionalmente os colaboradores; intensificação da formação em inteligência emocional para a liderança.

2) Saúde física: contratação de profissional de fisioterapia para a realização de sessões de ginástica laboral online; assessoria online de fisioterapeuta para verificar ajustes ergonômicos dos colaboradores; realização de palestra em convênio com o provedor da assistência médica contendo dicas de saúde e bem-estar, dando ênfase em medidas de prevenção à COVID-19.

3) Integração de colaboradores: realização de happy hour online quinzenalmente com a participação de cantores ou bandas ao vivo e mensagens da liderança; em datas de aniversário, a reunião online promovida pelo RH para a celebração da data com os aniversariantes. 
4) Estrutura: disponibilização de materiais ergonômicos conforme orientações do fisioterapeuta contratado; dicas de otimização de rede de internet pela equipe de Tl; avaliar a viabilidade de que a empresa forneça auxílio financeiro para a melhoria do plano de internet residencial dos colaboradores.

\section{REFERÊNCIAS}

AFFONSO, L. M. F.; FERRARI, F. L. Teorias da administração. Porto Alegre: Sagah, 2018.

ALMEIDA, J. S. C.; OLIVEIRA, S. O. Planejamento estratégico em empresas de pequeno porte: estudo em uma empresa de medicina laboratorial em Serrinha-BA. Revista Gestão \& Sustentabilidade, v. 2, n. 1, p. 38-56, 2020. DOI: https://doi.org/10.36661/2596142X.2020v2i2.9780.

BARBOSA, E. R.; BRONDANI, G. Planejamento estratégico organizacional. Revista Eletrônica de Contabilidade, v. 1, n. 2, p. 107-123, dez./fev. 2004. DOI: https://doi.org/10.5902/198109466235.

CSASZAR, F. A.; OSTLER, J. A contingency theory of representational complexity in organizations. Organization Science, v. 31, n. 5, p. 1053-1312, sep./oct. 2020. DOI: https://doi.org/10.1287/orsc.2019.1346.

FERNANDES, D. R. Uma visão sobre a análise da matriz SWOT como ferramenta para elaboração da estratégia. Revista de Ciências Jurídicas e Empresariais, v. 13, n. 2, p. 57-68, 2012. DOI: https://doi.org/10.17921/2448-2129.2012v13n2p\%25p.

GIARDINO, C.; UNTERKALMSTEINER, M.; PATERNOSTER, N.; GORSCHEK, T.; ABRAHAMSSON, P. What do we know about software development in start-ups? IEEE Software, v. 31, n. 5, p. 28-32, sep./oct. 2014. DOI: https://doi.org/10.1109/ms.2014.129.

LEENDERS, M. R.; ERSKINE, J. A. Case research: the case writing process. 3. ed. Ontario: The University of Western Otario, 1989.

MARCUS, L. J.; DORN, B. C.; HENDERSON, J.; MCNULTY, E. J. Meta-Leadership: a framework for building leadership effectiveness. National Preparedness Leadership Initiative, 2015. Disponível em: http://cdn1.sph.harvard.edu/wpcontent/uploads/sites/2443/2020/01/Meta-leadership-Overview-Working-Paper-Final.pdf. Acesso em: 06 jul. 2020.

MARCUS, L. J.; MCNULTY, E. J.; DORN, B. C.; GORALNICK, E. Crisis meta-leadership lessons from the boston marathon bombings response: the ingenuity of swarm intelligence. National Preparedness Leadership Initiative, 2014. Disponível em: http://cdn1.sph.harvard.edu/wp-content/uploads/sites/2443/2016/09/Marathon-BombingLeadership-Response-Report.pdf. Acesso em: 06 jul. 2020.

MARCUS, L. J.; MCNULTY, E. J.; FLYNN, L. B.; HENDERSON, J. M.; NEFFENGER, P. V.; SERINO, R.; TRENHOLM, J. The pop-doc loop: a continuous process for situational awareness and 
situational action. Industrial Marketing Management, v. 88, p. 272-277, 2020. DOI: https://doi.org/10.1016/j.indmarman.2020.05.019.

MORAES, S. Startup? Serviço Brasileiro de Apoio às Micro e Pequenas Empresas, 2020. Disponível em: <http://www.sebrae.com.br/sites/PortalSebrae/ufs/pi/artigos/voce-sabe-oque-e-uma-startup-e-o-que-ela-faz,e15ca719a0ea1710VgnVCM1000004c00210aRCRD.> Acesso em: 06 jul. 2020.

MOTTA, F. C. P.; VASCONCELOS, I. F. G. Teoria geral da administração. 3. ed. São Paulo: Pioneira Thomson Learning, 2016.

NOBRE, F. S.; TOBIAS, A. M.; WALKER, D. S. Uma visão da empresa baseada em habilidades: contextos estratégicos e contingenciais. Revista de Administração Contemporânea, v. 15, n. 3, p. 413-432, mai./jun. 2011. DOI: https://doi.org/10.1590/S1415-65552011000300004.

OLIVA, F. L.; KOTABE, M. Barriers, practices, methods and knowledge management tools in startups. Journal of Knowledge Management, v. 23, n. 9, p. 1838-1856, 2019. DOI: https://doi.org/10.1108/JKM-06-2018-0361.

SEBRAE - SERVIÇO BRASILEIRO DE APOIO ÀS MICRO E PEQUENAS EMPRESAS. Inovação: o que é uma empresa startup, 2020. Disponível em:

http://www.sebrae.com.br/Sebrae/Portal\%20Sebrae/Anexos/O+que+é+uma+empresa+start up.pdf. Acesso em: 06 jul. 2020.

TOLFO, S. R. Diferentes abordagens no estudo de liderança. In: BITTENCOURT, C. Gestão contemporânea de pessoas: novas práticas, conceitos tradicionais. 2. ed. Porto Alegre: Bookman, 2010. p. 197-216. 